\title{
Image Representative as an Alternative Reading Technique for Dyslexic Children
}

\author{
Nik Nor Azidah Nik Aziz ${ }^{1 *}$, Nurul Asyiqin Mohd Radzuan ${ }^{1}$ Khairul Zikri Abdullah ${ }^{2}$ and Wan Zamani \\ Wan Zakaria ${ }^{1}$ \\ ${ }^{1}$ Faculty of Art \& Design, Universiti Teknologi MARA, 42300 Bandar Puncak Alam, Malaysia \\ ${ }^{2}$ Faculty of Art \& Design, Universiti Teknologi MARA, 40450 Shah Alam, Malaysia \\ *Corresponding author email: nikazidah@uitm.edu.my
}

Published: 28 September 2020

\begin{abstract}
Dyslexic children who are said to have problems in learning actually have their unique learning styles. Thus, they required learning aids that are suitable with their conditions which are not similar with normal children. One of the issues of dyslexic children is the ability to figure out on how to peruse. Reading aptitudes are the most critical essential abilities. Without this ability, learning process is very challenging. Perceiving this significance and the motivation to support the dyslexic children, pondering or identification activity is led to distinguish the type of reading aids that are suitable to the necessities and requirements of dyslexic children. The case study was successfully conducted with children (6 to 9 years old) by Malaysian Dyslexia Association in Klang Valley, Malaysia. The finding from this preliminary research shows that reading in the form of interactive motion is easily accepted by the dyslexia children. In fact, the finding from this study provides a valuable learning style for these dyslexic children to use and practice. This new learning style is very enjoyable and manage to engage the children to read more in the classroom.
\end{abstract}

Keywords: Dyslexia, Dyslexic Children, Interactive Motion, Reading

eISSN: 2550-214X (C) 2020. The Authors. Published for Idealogy Journal by UiTM Press. This is an Open Access article distributed under the terms of the Creative Commons Attribution-NonCommercial-NoDerivatives License (http://creativecommons.org/licenses/by-nc-nd/4.0/), which permits non-commercial re-use, distribution, and reproduction in any medium, provided the original work is properly cited, and is not altered, transformed, or built upon in any way.

\section{INTRODUCTION}

Dyslexia is not a disease, but it is a particular learning disability that prompts certain troubles in the youngster's learning procedure especially in reading and writing. Several studies have revealed that dyslexia is more than just difficulty with translating letters into sounds. Some psychologists, dyslexia is not a disease it occurs in children with normal vision and nothing to do with the hearing, sight and brain damage (Vicari et al., 2005; Shaywitz, 2003; Berninger et al., 2008). This is also supported by Sariah Amirin, the President of Persatuan Dyslexia Malaysia (PDM) says that it happens because the brain lacks a function to translate the image seen or heard into something meaningful (Amirin, 2009). However, there is inconsistency with this argument, this view is supported by many dyslexics have problems with clearly seeing letters and their order. These difficulties may be caused by abnormal development of their visual, these mediate the ability to rapidly identify letters and their order because they control visual guidance of attention and of eye fixations (John Stein, 2014).

As we know that reading is very important for children at the early age, because if they could not read, they will never know how to write or spell the words that they learn. Once your child is in school, dyslexia signs and symptoms may become more apparent, including: Reading at a level well below the expected level for the age of your child, problems processing and understanding what he or she hears, difficulty comprehending rapid instructions, trouble following more than one command at a time, issues recollecting the grouping of things, trouble seeing (and infrequently hearing) similitudes and contrasts in letters and words, a failure to sound out the elocution of a new word, seeing letters or words backward ("b" for "d" or "saw" for "was," for instance), this is common in young children, but maybe more 
pronounced in children with dyslexia, difficulty spelling, and trouble learning a foreign language. (Dyslexia Basics, 2012. p.2). As dyslexia is part of learning disability that prompts certain troubles in the youngster's learning procedure, it is essential for the general population around them such as guardians, instructor, kin and companions to comprehend their issues with the goal that they can get the fundamental offer assistance. The person with dyslexia can really wind up plainly confounded when a few guidelines are given in the meantime, and will, for the most part, have a poor-here and now memory, trouble with a directional introduction, for example, telling right from left and guide reading. All the previously mentioned challenges affect dyslexic children to peruse, compose, explore, grasp and review significant data (Rainger, 2003).

Learning styles are defined as individual's preferences of acquiring and using information when learning (Herod, 2002). Today, using words in classroom to deliver information to the students are predominant. Therefore, most of the teachers are still using a conventional teaching method which teaching from a textbook in classroom. In fact, dyslexia children are having a reading problem since their early age. They do not even recognize letters, having a difficulty in pronouncing words and hardly to make sounding for a word or letter. Moreover, children today are living in a technology world that full of visual, animation, audio and text. Several studies have revealed that the positive effects of pictures presented with text were found mainly among individuals with low literacy (Houts et al., 2006) and multimedia in general is the most active absorbing experience from which children that can be develop visual perceptual and attentional abilities (Sandro Franceschini, Sara Bertoni, Luca Ronconi, Massimo Molteni, Simone Gori, Andrea Facoetti, 2015).

There have been few studies on the effects of multimedia research on learning in individuals with severe reading disabilities (e.g., dyslexia). Using multimedia elements to motivate and encourage dyslexic children is a proven approach. Spafford and Grosser (Sapfford, 1996) expressed that for the student with dyslexia, rehashed readings, retelling, etc would be expected to strengthen exhibited materials. According to Alty and Beacham (Alty, 2006), recommended utilizing words and pictures and in addition sound-related and portrayal without comparing on-screen content. Mason et al. (2013) used integrated text and picture materials and operationalized integrative processing as shifts of eye fixation from text to picture or vice versa. However, this facilitative effect of shifting attention within the same sensory modality (visual) was not obtained when inputs occurred simultaneously in two modalities (visual and audial).

Therefore, in this $21^{\text {st }}$ century students might need some visual aids in their learning style instead of just reading a textbook. Thus, it is aimed to enhance the learning style from conventional method to image representative that would attract dyslexic children to learn in classroom. It is the goal of this research to address the uses of pictures through a visually based research project studying the photographic practices of a group of dyslexic children. The objectives are to identify the current practice styles for dyslexic children and to develop image representative for dyslexic children. With every one of the advantages expressed above, multimedia has opened up a totally new world to dyslexic understudies, one that could enable them in their learning to handle. Multimedia presentation techniques do have a potential in providing outstanding support for dyslexic children (Heymans, 2007). In light of the subtle elements examined before, the courseware created was tried to assess its viability to distinguish the components or components that ought to be fused into the courseware to guarantee that it will give full profit to dyslexic children.

\section{METHODS}

This research is focusing closely on teaching reading fluency and comprehension strategies as part of a complete reading program. It is limited to dyslexic children at PDM Klang Valley, Malaysia involving the children in the age group from 6 to 9 years old with total number of 75 children. Due to substantial number of potential members in the examination populace, the populace engaged with the present investigation concentrated just on individuals who were considering inside the PDM Klang Valley, Malaysia. 
The procurement of subjective information which is the type of materials, confirmation and data, was mainly gotten from interview, perception and investigation on the materials which were recorded through digital camera and tape recorder (Creswell, 2013). Meanwhile, (Patton, 2002) emphasises the advantage of the qualitative research by revealing;

"The qualitative method permits the evaluator to study selected issues, cases, or events in depth and detail; in fact, that predetermined categories of analysis do not constrain the data collection contributes to the depth and detail of qualitative data".

This case study is to enhance learning styles of dyslexic children in a classroom by using visual aids. The analyses involved on investigation with their actual pith and research contemporary genuine marvel through detailed logical examination of a set number of occasions or conditions, and their connections.

A face-to-face interview was conducted with PDM teachers twice. Teachers were answering question asked by the researcher about learning styles of the dyslexic children. Then, 75 dyslexic children were tested with the test set provided by the researcher. A pre-test was carried out before the researcher starting the test on the understanding the colour on still image. The children learn in a conventional learning style could not attract them to stay still while learning and they are easily losing focus while in classroom. The significance of meeting as underlined by Richards and Morse (2012), "A meeting is both the most conventional and the most remarkable approach that can be utilized to find a separately one of a kind affair".

Furthermore, meet speaks to the next significant information wellspring of this investigation. The meetings concentrating more on learning style and showing the process for dyslexic youngsters, for example, the significance of visual guides in the classroom. The final interview focused primarily on the research questions of the case study: what were the issues that emerged, what helped or hindered our coordinated effort, and what benefits did they get from the researcher. Researcher transcribed each interview and added additional notes for interpretation. Finally, the interviews were additionally useful in the planning of assignments for the Post-test.

After screening, the participant observation was conducted four times at the centre with number of children reduced to 43 involving 4 different age groups $(6,7,8$ and 9 years old) that showed in Figure 1. During the participant observation, all the activities were video and photographed recorded. The inclusionary criteria for this sample of group included; (i) be able to perceive the visual and (ii) creatively create the imagination to think about the image representative to create vivid mental images to retain information. The dyslexic children respond has been analysed by the researcher for an amendment in order to reach the final version of the activities. Pre-test and test of 3D Images identification activities took about one month to be completed. 


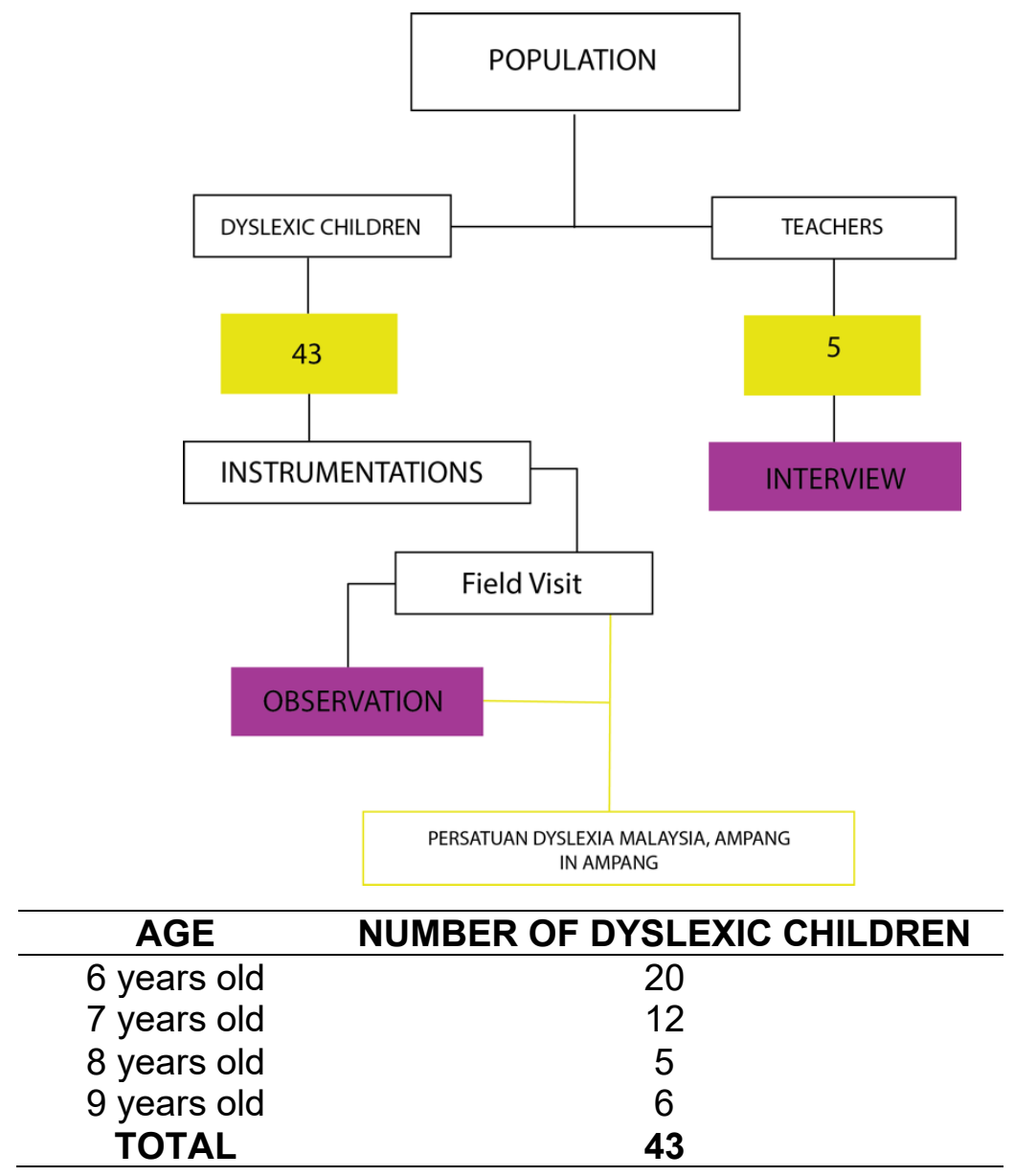

Figure 1: Summary Data Collection for Post-Test 


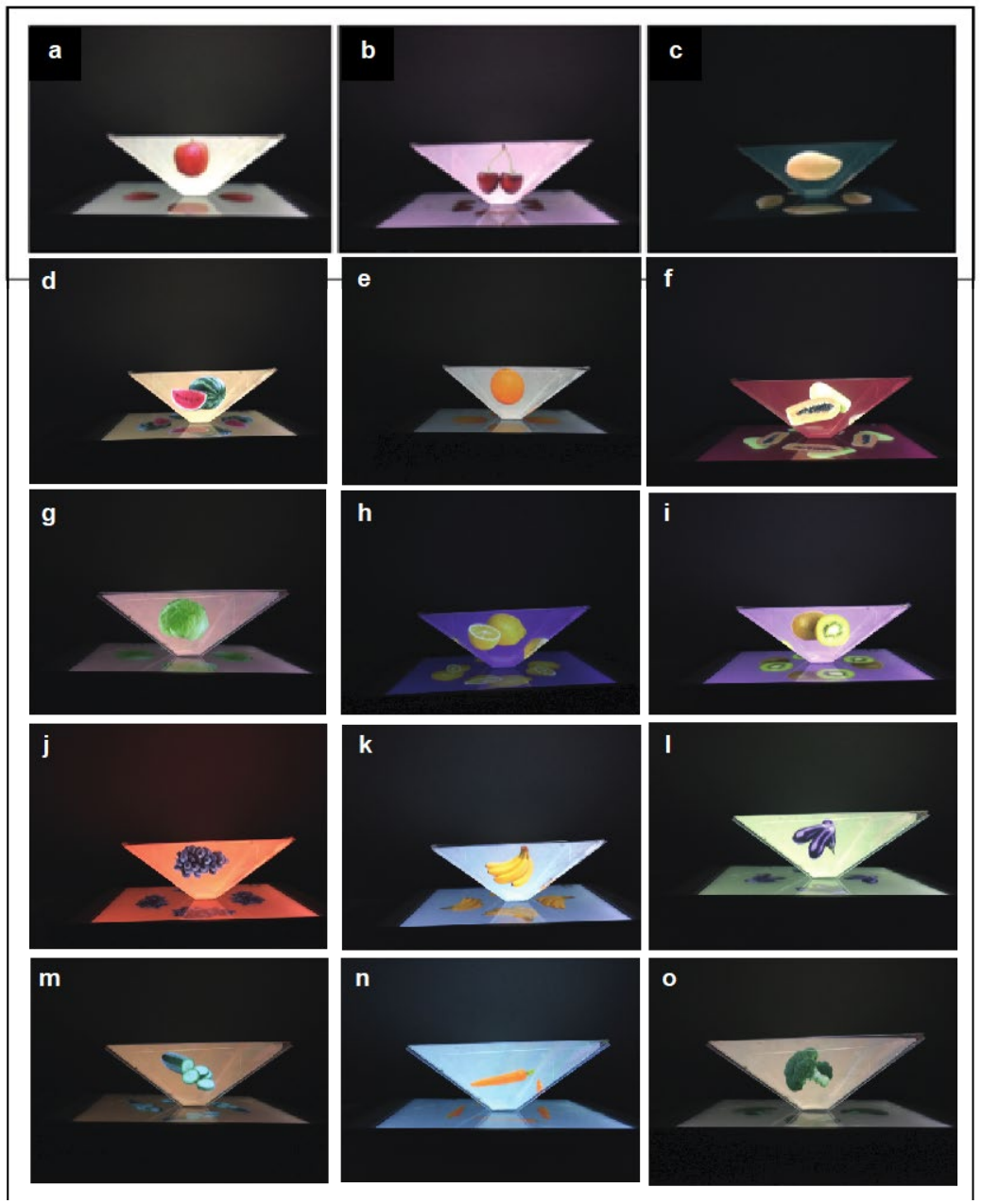

Figure 2: Holographic images (3D) that the researcher conducted a test for dyslexic children a) apple b) cherry c) mango d) watermelon e) orange f) papaya g) cabbage h) lemon i) kiwifruit j) grapes k) banana I) eggplant $\mathrm{m}$ ) cucumber $\mathrm{n}$ ) carrot, and o) broccoli

All of these images above were applied in image representative and colours. As dyslexic children are more attracted to bright colours or in pastel colours in their learning lesson, this learning style helped them to enhance their reading skill. The researcher turned the flash card using the actual images instead of illustrated those images and come out with a final prototype. It is because to make it more realistic and create an imagination to dyslexic children to understand and could name those fruits without having any troubles.

\section{RESULTS AND DISCUSSION}

The face-to-face interview that was conducted by the researcher with 5 teachers at PDM showed that teachers were still using a conventional method of teaching style for the dyslexia children. This is due to limited resources in Malaysia. The teachers used; (i) cycle motor teaching method, (ii) one to one between teacher and dyslexic children, (iii) black and white illustration and (iv) no graphical nor visual aids. In addition to this, some dyslexic children who were easily losing focus, cannot stay still for too long and not attracted to this conventional method of learning styles. Before the researcher end the interview session, teachers informed that there were no interactive or visual aids for these dyslexic children in their learning styles. With those interactive motion that the researcher provided during the test, the children were more excited and enjoyed more during the lesson and the teachers could see the effectiveness of image representative as dyslexic children can differentiate the shapes and colours from what they see instead of using illustration or graphic. 
Table 1 shows the numbers of involvement of dyslexic children in PDM are grouped 6 to 9 years old. The finding shows that, almost all children were able to identify the 3D objects regardless of age groups. The children who were not able to identify the $3 \mathrm{D}$ images was found to have severe dyslexia problem.

Table 1: Participation of dyslexic children in 3D object identification activity

\begin{tabular}{cccc}
\hline $\begin{array}{c}\text { Age Groups } \\
\text { (Years Old) }\end{array}$ & $\begin{array}{c}\text { Number of Dyslexic } \\
\text { Children }\end{array}$ & $\begin{array}{c}\text { Ability to Identify 3D Object } \\
\text { Able }\end{array}$ & $\begin{array}{c}\text { Not Able } \\
\text { (yeld }\end{array}$ \\
\hline 6 & 20 & 20 & 1 \\
7 & 12 & 11 & 0 \\
8 & 5 & 5 & 1 \\
9 & 6 & 4 & \\
\hline
\end{tabular}

Figure 3 below shows the identification of 3 images among dyslexic children. The test was enjoyable and more children were able to understand about the actual images and differentiate the colours shown on the post-test as shown on the figures above, there were all 6 years old dyslexic children were able to succeed on the post-test. In addition, there were 11 dyslexic children who pass the Post-test except for 1 student who were unable to understand the visual shown by the researcher. Followed by 5 dyslexic children who passed on the Post-test and two failed from 6 dyslexic children age 9.

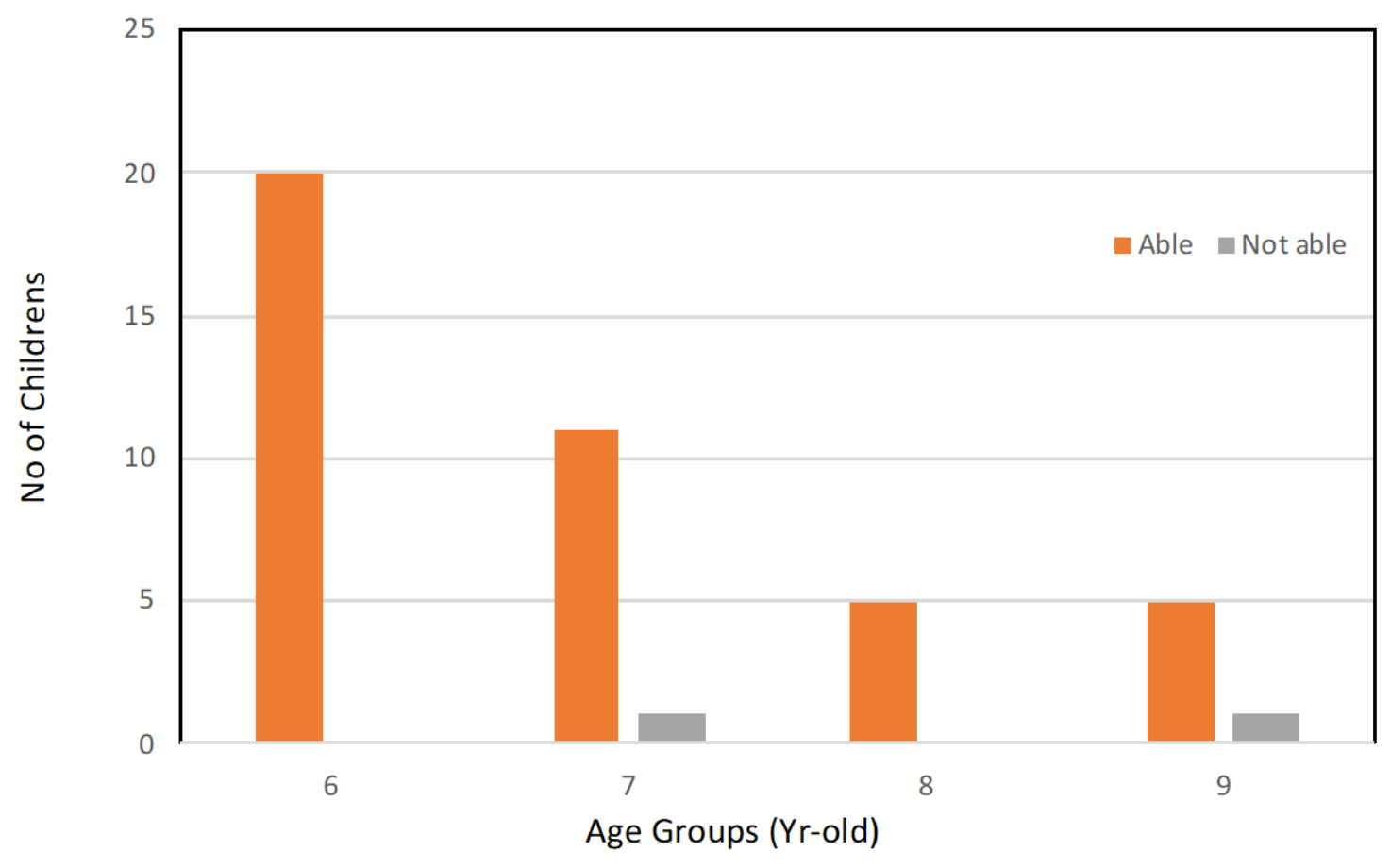

Figure 3: The identification test of 3D images among dyslexic children.

Based on the data presented, dyslexic children are really enjoyed the session in $3 \mathrm{D}$ object identification activities. Even though the session took short time of period, the observation results highly convincing that image representative as an alternative reading potentially to be used in future. In terms of learning style, the outcomes from teachers interview impressively offered that learning style affected by teaching materials. Different teaching materials given different results on leaning style. 


\section{CONCLUSION}

The focus of this study is to develop an interactive motion for dyslexic children. Based on the result and discussion, it can be concluded that the enhancement of learning style from conventional method to image representative was successfully attracted the dyslexic children to participate more in learning while in the classroom. The researcher finally found that interactive motion is very helpful to attract and create an interaction with the dyslexic children in classroom. The children tend to be more progressive by seeing those actual images neither their teachers too.

\section{ACKNOWLEDGEMENT}

Authors would like to acknowledge the Faculty of Art \& Design, UiTM for the support and facilities provided during this project. Special thanks to UiTM Puncak Alam for the funding provided under DUCS funds.

\section{REFERENCES}

Beachem, N. (n.d). The potential of multimedia to enhance learning for students with dyslexia? Retrieved from http://www.skillsforaccess.org.uk/articles.php?id=150

Beatrice, J.A. (1994). Learning to study through critical thinking? Retrieved from http://www.uu.edu./programs/tesl/ElementarySchool/learningstylesinventory.htm

Caylak, E. (2010, January 12). The Studies about Phonological Deficit Theory in Children with Developmental Dyslexia: Review. Retrieved from https://pdfs.semanticscholar.org/e914/a839d5ba64a4dc93c3ef312dfa7300f3b3ab.pdf

Creswell, J. W. (2013). Qualitative Inquiry \& Research Design: Choosing among Five Approaches (3rd ed.). Thousand Oaks, CA: SAGE.

Herod, L. (2002). Adult learning: From theory to practice. Retrieved from http://www.nald.ca/adultlearningcourse/glossary.htm

Holmqvist Olander, M., Wennås Brante, E., \& Nyström, M. (2017). The Effect of Illustration on Improving Text Comprehension in Dyslexic Adults. Dyslexia (Chichester, England), 23(1), 42-65. https://doi.org/10.1002/dys. 1545

John S. (2014). Dyslexia: The Role of Vision and Visual Attention. Development Dyslexia (T Wydell, Section Editor) http://doi.10.1007/s40474-014-0030-6

Joshua R., Virginia M. (2005) Using Auditory-Visual Speech to Probe the Basis of Noise-Impaired Consonant-Vowel Perception in Dyslexia and Auditory Neuropathy. The Journal of the Acoustical Society of America 118, 1122 (2005); https://doi.org/10.1121/1.1940509

Patton, M. Q. (2002). Qualitative Research \& Evaluation Methods. 3rd edition. Sage Publications, Inc.

Rainger, R. (2003). A dyslexic perspective on e-content accessibility. York, UK: JISC TechDis.

Rose, S. J. (2009). Identifying and Teaching Children and Young People with Dyslexia and Literacy available through website: https://dera.ioe.ac.uk/14790/7/00659-2009DOM-EN_Redacted.pdf

Sandro F., Sara B., Luca R., Massimo M., Simone G. Andrea F., (2015). "Shall We Play a Game?”: Improving Reading Through Action Video Games in Developmental Dyslexia. Development Dyslexia (T Wydell, Section Editor) http://doi.10.1007/s40474-015-0064-4

Shaywitz, S. (2003). Overcoming dyslexia: A new and complete science-based program for reading problems at any level. New York, NY: Alfred A. Knopf 
Idealogy Journal

Volume 5 Issue 22020
溇: IDEALOGY

JOURNAL 